\title{
Are there gaps in the provision of perinatal care in Greece?
}

\author{
CHRYSSA TZOUMAKA-BAKOULA, ${ }^{1}$ VASSO LEKEA-KARANIKA, \\ N S MATSANIOTIS, ${ }^{1}$ T SHENTON, ${ }^{2}$ AND JEAN GOLDING ${ }^{2}$ \\ From ${ }^{1}$ the 1st Department of Paediatrics of Athens University, Hospital for Sick Children "Agia Sophia", Goudi, \\ Athens, Greece, and ${ }^{2}$ Department of Child Health, University of Bristol, United Kingdom.
}

\section{ABSTRACT}

Study objective: The objective was to test the hypothesis that easy access to sophisticated hospitals is associated with a reduction in perinatal mortality.

Design: The study was a nationwide questionnaire survey of a birth cohort.

Subjects: All deliveries $>500 \mathrm{~g}$ weight of singleton live births and stillbirths occurring throughout Greece during April 1983 were included. Completed questionnaires were returned for 10953 deliveries (8\% of total annual registered births in Greece), and data on 10790 singleton births were analysed, including 127 stillbirths and 137 early neonatal deaths.

Measurements and main results: The questionnaires contained information on demographic characteristics of each parent, mother's reproductive history, and clinical course of pregnancy, labour and perinatal period. Mothers living in big urban centres were compared with the rest of the country. Overall mortality rates were similar but births in the big urban centres were of significantly lower weight due to fetal growth retardation. Logistic regression analysis, taking account of birthweight, parity, maternal age, and maternal education showed that there was an advantage to mothers living in big urban centres, perinatal mortality being $63 \%$ higher in the rest of the country $\left(\chi^{2}=7 \cdot 4, \mathrm{p}<0.01\right)$.

Conclusion: The evidence obtained supports the original hypothesis and suggest that a reduction in the high perinatal mortality rate in Greece may be achieved by restructuring the perinatal services.

Several population studies have attempted to assess whether areas in which there are reduced facilities for obstetric or neonatal care have higher perinatal mortality rates than areas where the provision of care is better. Information from Norway, ${ }^{1}$ when the perinatal mortality rate among singletons was 21 per 1000 , showed that the perinatal mortality rate was lowest where the obstetric service provision was best. More recent data from Norway ${ }^{2}$ and Holland ${ }^{3}$ have shown that among low birthweight livebirths there has been evidence for better survival rates in areas where the provision of care was exceptionally good. Nevertheless, the issue is not clear cut and the debate continues.

Greece is a country with large underpopulated areas. Half the total population, however, is concentrated in Athens. The only other major city in Greece is Salonika (in Macedonia). There are large University Centres in both cities.

Data from Greece have been obtained for a population sample born in April $1983,{ }^{4}$ when the perinatal mortality rate was 21.6 per 1000 singleton births. In analysing perinatal mortality, it is important to distinguish between the area of residence of the mother, which is an indication of the facilities available to her and which she can reach relatively easily, and the area in which the mother was actually delivered. These may be different, since high risk mothers are often transferred into those areas with better facilities. Indeed, within the Greek National Survey $15 \%$ of all mothers had delivered in a county in which they did not actually reside. The majority of such movements were in fact to the two major centres of Athens and Salonika.

A major reason for looking at the provision of care in Greece lies in the fact that the Greek National Perinatal Survey of 1983 showed that the perinatal mortality rate was as high as 23.8 per thousand, far in excess of that for most European countries at this time. Such a high rate was not due to high rates of low birthweight deliveries, since only $5.8 \%$ of the total births were of birthweight below $2500 \mathrm{~g} .{ }^{4}$ Nor was the 
high mortality rate explained by high rates of hypertension in pregnancy or fatal central nervous system malformations. The incidence of hypertension in pregnancy was far lower in Greece ${ }^{5}$ than that found, for example, in Britain, and the mortality due to central nervous system malformations ${ }^{6}$ was also lower than that found in Britain. In fact the majority of the deaths in Greece were associated with intrapartum asphyxia or immaturity. ${ }^{7}$

It is important to try and identify ways in which the mortality rate may be profitably reduced. In this paper we test the assumption that the perinatal care in parts of Greece may be inadequate.

\section{Methods}

Data were collected on all live births and stillbirths weighing more than $500 \mathrm{~g}$ which occurred throughout Greece during the 30 consecutive days of April 1983. Questionnaires were filled in by obstetricians and/or midwives at the time of delivery $(99 \%$ of deliveries occur in hospital in Greece). The babies were followed up to the age of 7 days and all deaths occurring by that time were identified. The questionnaire contained information regarding demographic characteristics of each parent, the mother's reproductive history, the clinical course of the pregnancy, and history of labour, delivery and the early neonatal period. ${ }^{4}$

The survey's death records were compared to death notifications registered in both peripheral and the central registration offices. These linked data constituted the data file for analyses. Further details of the methodology and content of the questionnaire are to be found elsewhere. ${ }^{4}$

For the analyses presented in this paper only singleton births have been considered. Those cases where the mother's region of residence was not recorded have also been excluded.

\section{Results}

At the end of the study period, 11048 completed questionnaires corresponding to 10953 deliveries were returned. This sample was $8 \%$ of the total annual registered births in the country and is therefore largely representative of the total births in Greece. Included among these were 264 perinatal deaths (127 stillbirths and 137 early neonatal deaths). The number of perinatal deaths reported in this survey was far in excess of those registered centrally. ${ }^{8}$

From the geographic pattern shown in table 1 it can be seen that there appeared to be some variation in perinatal mortality with the region of residence of the mother. In particular, mothers resident in the two major urban regions, Macedonia and Greater Athens, had two of the three lowest mortality rates. The numbers in many of the rural regions were small and thus the confidence intervals around their mortality rates are wide. Overall the distribution of deaths was not statistically different from the distribution of survivors $\left(\chi_{8}^{2}=13.9 ; p>0.05\right)$.

Table 1 Mortality among singleton births by region in which mother lives, with $95 \%$ confidence intervals $(C I)$

\begin{tabular}{lrccl}
\hline $\begin{array}{l}\text { Region of } \\
\text { residence }\end{array}$ & Total & Stillbirths & $\begin{array}{l}\text { Early } \\
\text { neonatal } \\
\text { deaths }\end{array}$ & $\begin{array}{l}\text { Perinatal } \\
\text { mortality } \\
\text { rate }(95 \% \text { CI) }\end{array}$ \\
\hline Athens & 4072 & 46 & 35 & $19 \cdot 9(15 \cdot 7,24 \cdot 1)$ \\
Mainland & 819 & 5 & 11 & $19 \cdot 5(10 \cdot 1,29 \cdot 0)$ \\
Peloponese & 1037 & 12 & 15 & $26 \cdot 0(16 \cdot 2,35 \cdot 9)$ \\
Thessaly & 601 & 8 & 13 & $34 \cdot 9(20 \cdot 3,49 \cdot 6)^{*}$ \\
Epiros & 370 & 4 & 4 & $21 \cdot 6(6 \cdot 6,36 \cdot 6)$ \\
Macedonia & 2297 & 16 & 22 & $16 \cdot 5(11 \cdot 3,21 \cdot 8)$ \\
Thrace & 377 & 7 & 7 & $37 \cdot 1(17 \cdot 7,56 \cdot 6)$ \\
Islands & 652 & 7 & 8 & $23 \cdot 0(11 \cdot 4,34 \cdot 6)$ \\
Crete & 565 & 8 & 5 & $23 \cdot 0(10 \cdot 5,35 \cdot 5)$ \\
All known & 10790 & 113 & 120 & $21 \cdot 6(18 \cdot 9,24 \cdot 3)$ \\
\hline
\end{tabular}

*significantly different from rest of country $\chi_{1}^{2}=4.7, p<0.05$.

The hypothesis being tested in this paper is that access to centres presumed to be better organised was associated with a reduction in perinatal mortality. In the remainder of this paper we therefore compare total births in those women living in either Greater Athens or Salonika (the "big urban centres") with those living elsewhere in Greece. There were small differences in perinatal mortality rates between the two types of area-the differences were only apparent for early neonatal deaths and not for stillbirths (table 2) but statistical significance was not reached.

Table 2 Perinatal death rates by maternal place of residence (number of deaths in parentheses).

\begin{tabular}{lcll}
\hline & $\begin{array}{l}\text { Big urban } \\
\text { centres }(a)\end{array}$ & $\begin{array}{l}\text { Rest of } \\
\text { country (b) }\end{array}$ & $(b) /(a)$ \\
\hline Perinatal death rate & $19.7(99)$ & $23.2(134)$ & $1.2 \mathrm{NS}$ \\
Fetal death rate & $10.3(52)$ & $10.6(61)$ & $1.0 \mathrm{NS}$ \\
Early neonatal death rate $9.4(47)$ & $12.7(73)$ & $1.4 \mathrm{NS}$ \\
Total number of births & 5023 & 5767 & \\
\hline
\end{tabular}

$\mathrm{NS}=$ Not statistically significant

Birthweight and gestation are important associations of perinatal death. It can be seen from table 3 that the mothers residing in the big urban centres were significantly more likely to have delivered a baby of birthweight under $3000 \mathrm{~g}(18.7 \%)$ than those living in the rest of the country $(16.1 \%)(p<0.01)$; this was not due to variations in gestational age (table 4 ) but rather to the risk of slight growth retardation (table 5). It would therefore be logical to assume that 
Table 3 Birthweight distribution of singleton births by mother's place of residence (number of deaths in parentheses).

\begin{tabular}{|c|c|c|}
\hline Birthweight (g) & Big urban centr & Rest of country \\
\hline $\begin{array}{l}<1500 \\
1500-2499 \\
2500-2999 \\
3000+\end{array}$ & $\begin{array}{c}1 \cdot 2 \%(61) \\
3.6 \%(179) \\
13.9 \%(697) \\
81 \cdot 3 \%(4069)\end{array}$ & $\begin{array}{c}1 \cdot 1 \%(64) \\
3 \cdot 1 \%(178) \\
11.9 \%(685) \\
83.9 \%(4827)\end{array}$ \\
\hline All known & $100 \%(5006)$ & $100 \%(5754)$ \\
\hline
\end{tabular}

$\chi_{3}^{2}=12 \cdot 8, \mathrm{p}<0.01$

Table 4 Gestation distribution of singletons by mother's place of residence (number of deaths in parentheses).

\begin{tabular}{lcc}
\hline Gestation (weeks) & \multicolumn{3}{c}{ Big urban centres } & Rest of country \\
\hline$<37$ & $8 \cdot 4 \%(407)$ & $8 \cdot 1 \%(440)$ \\
$37-42$ & $89.9 \%(4334)$ & $89 \cdot 8 \%(4901)$ \\
$43+$ & $1 \cdot 6 \%(79)$ & $2 \cdot 1 \%(116)$ \\
All known & $100 \%(4820)$ & $100 \%(5457)$ \\
\hline
\end{tabular}

$\chi_{3}^{2}=3 \cdot 6$, NS.

Table 5 Distribution of growth retarded singletons by mother's place of residence (number of deaths in parentheses).

\begin{tabular}{lcc}
\hline Growth & \multicolumn{2}{c}{ Big urban centres } \\
\hline $\begin{array}{l}\text { Normal } \\
-1 \text { SD up to }-2 \text { SD of mean country }\end{array}$ \\
$\begin{array}{l}\text { birthweight } \\
<-2 \text { SD of mean birthweight } \\
\text { (growth retarded) }\end{array}$ & $12.3 \%(591)$ & $10.0 \%(548)$ \\
All known & $1.7 \%(82)$ & $1.5 \%(80)$ \\
\hline
\end{tabular}

$\chi_{2}^{2}=14 \cdot 13, \mathrm{p}<0.01$

mothers resident in the big urban centres should have had a slightly higher perinatal mortality rate than the rest of the country. In table 6 are the birthweight specific mortality rates for the two groups of regions: for three of four birthweight groupings the mortality rates in the big urban centres were lower than those in the rest of the country, and this was statistically significant for those of birthweight $1500-2499 \mathrm{~g}$.

Table 6 Birthweight specific mortality rates by mother's place of residence (singletons only). In parentheses the numerator $=$ number of deaths, the denominator $=$ number of births.

\begin{tabular}{lcc}
\hline Birthweight $(g)$ & Big urban centres & Rest of country \\
\hline$<1500$ & $754 \cdot 1(46 / 61)$ & $781 \cdot 2(50 / 64)$ \\
$1500-2499$ & $78 \cdot 2(14 / 179)$ & $157 \cdot 3(28 / 178)^{*}$ \\
$2500-2999$ & $21 \cdot 5(15 / 697)$ & $20 \cdot 4(14 / 685)$ \\
$3000+$ & $4 \cdot 7(19 / 4069)$ & $7 \cdot 9(38 / 4827)$ \\
All known & $18.8(94 / 5006)$ & $22 \cdot 6(130 / 5754)$ \\
\hline
\end{tabular}

$* \mathrm{p}<0.05$
It may be presumed that residents of the big urban centres differ demographically from the residents of the rest of the country and this is indubitably true. Nevertheless we have shown elsewhere ${ }^{9}$ that apart from the expected association with advanced maternal age, the major sociodemographic variations with perinatal mortality in Greece are associated with parity. There is little association with other socioeconomic variables. Maternal education level is associated at the $5 \%$ level, but with highly educated mothers having as high a risk as the most poorly educated. Thus, in carrying out a logistic regression with perinatal death as outcome, it seemed that the only other independent variables to be taken into account were maternal education, maternal age, birthweight and parity. The results (table 7) clearly show that by taking account of differences in these factors between the two groups of regions, the

Table 7 Results of multiple regression analysis with outcome $=$ perinatal death (singletons only).

\begin{tabular}{|c|c|c|c|c|c|}
\hline Independent variab & & $\begin{array}{l}\text { Odds } \\
\text { ratio }\end{array}$ & $\chi^{2}$ & $d f$ & $p$ \\
\hline Parity & $\begin{array}{l}0 \\
1 \\
2 \\
3 \\
4+\end{array}$ & $\begin{array}{l}1 \cdot 00^{*} \\
0 \cdot 74 \\
1 \cdot 28 \\
1 \cdot 70 \\
2 \cdot 83\end{array}$ & $15 \cdot 3$ & 4 & $<0.01$ \\
\hline $\begin{array}{l}\text { Maternal age } \\
\text { (years) }\end{array}$ & $\begin{array}{l}<35 \\
35+\end{array}$ & $\begin{array}{l}1.00^{*} \\
1.88\end{array}$ & 5.6 & 1 & $<0.02$ \\
\hline $\begin{array}{l}\text { Maternal educatio } \\
\text { (years) }\end{array}$ & $\begin{array}{l}<6 \\
6-12 \\
13+\end{array}$ & $\begin{array}{l}1 \cdot 00^{*} \\
0 \cdot 77 \\
1.40\end{array}$ & 5.0 & 2 & NS \\
\hline Birthweight (g) & $\begin{array}{l}<1000 \\
1000-1499 \\
1500-1999 \\
2000-2499 \\
2500-2999 \\
3000-3499\end{array}$ & $\begin{array}{r}811 \cdot 76 \\
313 \cdot 34 \\
64 \cdot 76 \\
20 \cdot 64 \\
4 \cdot 91 \\
2 \cdot 42\end{array}$ & & & \\
\hline Area of residence & $\begin{array}{l}3500+ \\
\text { Big urban centres } \\
\text { Rest of country }\end{array}$ & $\begin{array}{l}1.00^{*} \\
1.00^{*} \\
1.63\end{array}$ & 749 & 6 & $<0.0001$ \\
\hline
\end{tabular}

*reference value

Table 8 Classification of singleton perinatal deaths by maternal residence.

\begin{tabular}{|c|c|c|c|c|}
\hline \multirow[b]{2}{*}{ Wigglesworth classification } & \multicolumn{2}{|c|}{ Big urban centres } & \multicolumn{2}{|c|}{ Rest of country } \\
\hline & $n$ & rate* & $n$ & rate* \\
\hline Macerated stillbirth & 17 & 3.4 & 11 & 1.9 \\
\hline Congenital defect & 20 & $4 \cdot 0$ & 29 & $5 \cdot 0$ \\
\hline Immaturity & 20 & $4 \cdot 0$ & 29 & $5 \cdot 0$ \\
\hline Intrapartum asphyxia & 33 & $6 \cdot 6$ & 58 & $10 \cdot 1$ \\
\hline Other & 9 & $1 \cdot 8$ & 7 & $1 \cdot 2$ \\
\hline \multirow[t]{2}{*}{ All } & 99 & $19 \cdot 7$ & 134 & $23 \cdot 2$ \\
\hline & \multicolumn{2}{|c|}{$(100 \%)$} & \multicolumn{2}{|c|}{$(100 \%)$} \\
\hline
\end{tabular}

*per 1000 total births. 
perinatal mortality rate becomes significantly different. The mortality rate in infants of mothers resident in the rest of the country was $63 \%$ higher than in infants of mothers resident in the big urban areas.

\section{WIGGLESWORTH CLASSIFICATION}

A comparison of the different classes of perinatal deaths derived using the Wigglesworth (1980) classification (table 8) shows that the only marked differences in incidence between the areas are found for deaths associated with intrapartum asphyxia.

\section{Discussion}

In this paper we have shown that when mothers were resident in regions where there were less organised services and less sophisticated facilities available for obstetric and paediatric care, the perinatal mortality rate appeared to be only slightly higher than that found for mothers resident elsewhere in Greece. If, however, account was taken of other factors associated with elevated mortality, a much clearer difference was seen. Mothers resident outside the big urban centres had a much greater risk of losing their baby in the perinatal period.

The Greek data may be directly compared with the first Norwegian study, since the perinatal mortality rates were almost identical. Bakketeig and his colleagues $^{1}$ showed clear differences between areas with different obstetric care provision among infants born of weight $1500-2499 \mathrm{~g}$ and $\geqslant 2500 \mathrm{~g}$ : areas with more sophisticated services had lower death rates. Similar trends were found in the Greek data although statistical significance was only reached in the birthweight group 1500-2499 g. In both countries the difference in rates was due to early neonatal deaths rather than stillbirths.

At the time of the Greek survey practically all births (99\%) occurred in hospital-30\% in state hospitals and $69 \%$ in private hospitals. All health insurance schemes cover the total costs for delivery in state hospitals. All but one cover all or a high proportion of the expenses for private hospitals, depending on the luxury of the room the mother has chosen. The exception is a scheme which covers agricultural workers and which only covers state hospital expenses.

Some $92 \%$ of births were attended in the 2 nd and 3rd stages by the obstetrician, who also delivered the baby. Midwives delivered only $7 \%$ of babies. Intervention rates are exceptionally high throughout Greece, with up to $50 \%$ of mothers being delivered under general anaesthetic. The ways in which intervention may influence outcome are complex and are the subject of current research by this team.

The Wigglesworth classification of perinatal deaths indicated that the differences between the areas appeared to be largely due to an increased proportion of deaths associated with intrapartum anoxia. This suggests that improvements in obstetric and paediatric care at around the time of delivery may improve the situation.

It is possible that some deaths occurring after the first week ought to have been attributed to the perinatal period. If these were more likely to occur in the "big urban centres" then our study would tend to overestimate the beneficial effects of residence in such areas. However, if this were true one would expect the difference in mortality to be found principally among the "deaths due to immaturity" rather than among deaths associated with "intrapartum asphyxia".

For countries like Greece, with relatively high mortality rates, variations found within the country emphasise the size of the problem in specific areas and indicate points for intervention. Over the years there has been considerable debate as to whether sophisticated obstetric and paediatric services can actually reduce the perinatal mortality rates. The debate has centred on the fact that with any new intervention, iatrogenic disease increases and the potential benefits of the intervention may be far exceeded by the disastrous consequences of the iatrogenic disorders. ${ }^{11}$ The data from Greece present some evidence that residence near experienced centres does actually carry some benefit to the fetus. We are unable to conclude, however, that technological techniques should be improved. It may be that the more experienced obstetricians are to be found in the big urban centres and that they have better knowledge of when to intervene.

Of course, epidemiological data can never prove cause and effect but the evidence presented here certainly supports the original hypothesis of this analysis. The results of this study thus suggest that a significant reduction in the high perinatal mortality rate in Greece may be achieved by a restructuring of the perinatal health services throughout the country. It is unlikely that further technology is required, but, rather, suitable training for the staff in the recognition and management of an asphyxiated baby. Hopefully the information presented here can be used as a useful tool by the health care planners and providers in any attempt to improve the situation in Greece.

Address for correspondence and reprints: $\mathrm{Dr} \mathrm{J}$ Golding, Institute of Child Health, Royal Hospital for Sick Children, St Michael's Hill, Bristol BS2 8BJ.

\section{References}

${ }^{1}$ Bakketeig LS, Hoffman HS, Steinthal PM. Obstetric service and perinatal mortality in Norway. Acta Obstet Gynecol Scand (Suppl) 1978; 57: 3-19. 
${ }^{2}$ Forbes JF, Larssen K-E, Bakketeig LS. Access to intensive neonatal care and neonatal survival in low birthweight infants: A population study in Norway. Paediatr Perinatal Epidemiol 1987; 1: 33-42.

${ }^{3}$ Verloove-Vanhorick SP, Verwey RA, Brand R. Neonatal care and neonatal survival (letter). Paediatr Perinatal Epidemiol 1988; 2: 104-6.

${ }^{4}$ Tzoumaka-Bakoula C. The Greek National Perinatal Survey: I: Design, methodology and case ascertainment. Paediatr Perinatal Epidemiol 1987; 1: 43-55.

${ }^{5}$ Tzoumaka-Bakoula C, Lekea-Karanika V, Golding J, Thomas P. Hypertensive disorders of pregnancy in Greece. Eur J Obstet Gynaecol Reprod Biol 1989; 31: $127-31$.

${ }^{6}$ Lekea-Karanika V, Tzoumaka-Bakoula C, Golding J. Incidence of anencephaly and spina bifida in Greece. Teratology 1988; 38: 347-9.
${ }^{7}$ Tzoumaka-Bakoula C, Lekea-Karanika V, Matsaniotis NS, McCarthy BJ, Golding J. Birthweight-specific mortality in Greece. Acta Paediatr Scand (in press).

${ }^{8}$ Tzoumaka-Bakoula C. Assessment of the incidence of perinatal deaths in Greece using two separate sources. In: The Third Report of the WHO study into Biological and Environmental Effects on Perinatal Mortality. Bristol: University of Bristol, 1989 (in press).

${ }^{9}$ Tzoumaka-Bakoula C, Lekea-Karanika V, Matsaniotis NS, Golding J. The Greek National Perinatal Survey II. Socio-economic factors and perinatal mortality in Greece. Paediatr Perinatal Epidemiol 1989; 3: 41-52.

${ }^{10}$ Wigglesworth J. Monitoring perinatal mortality: a pathophysiological approach. Lancet 1980; ii: 684-6.

${ }^{11}$ Wagner MR. Whose baby is it anyway? Paediatr Perinatal Epidemiol 1988; 2: 118-123. 